\title{
Polvo de estrellas \\ - nubes de polvo \\ El error fotográfico \\ en la Carta del Cielo \\ de Tacubaya
}

Mariana Rubio de los Santos

Universidad Nacional Autónoma de México

Star Dust or Clouds of Dust

Photography Error in Tacubaya's Carte du Ciel

Recepción: 31 de enero de 2020

Aceptación: 11 de junio de 2020 


\section{Resumen}

El Observatorio Astronómico Nacional de Tacubaya participó en el proyecto internacional La Carte du Ciel con el objetivo de fotografiar y cartografiar las posiciones de las estrellas hasta de la onceava magnitud; es decir, un brillo que no se alcanza a distinguir a simple vista. La producción visual, discursiva y textual de los astrónomos del observatorio permite poner en cuestión la práctica fotográfica mexicana de finales del siglo xIX y principios del xx y analizar cómo la visualidad se construyó desde los límites de lo visible a partir de un proceso complejo con protocolos de observación, de pruebas fotográficas, mediciones micrométricas, cálculos trigonométricos y ampliaciones impresas. Las imágenes que se obtienen son codificaciones científicas y formas de visualización experimental producto de la prueba y el error. Este artículo analiza las reflexiones en torno al error visual, donde se construye conocimiento mediante la interpretación de la visualidad de aquello visible e invisible a los ojos.

\section{Palabras clave}

Astrofotografía, error visual, Carte du Ciel, fotografía celeste, Observatorio Astronómico Nacional

\section{Abstract}

The National Astronomical Observatory of Tacubaya has taken part in the international project Carte du Ciel with the aim of photographing and mapping the positions of the stars up to the eleventh magnitude -i.e. a brightness not visible to the naked eye. The astronomers' visual, discursive, and textual production allows to inquire the late $19^{\text {th }}$ and early $20^{\text {th }}$ centuries' photographic practice and to analyze how visuality was built from the limits of the visible along a complex process with observation protocols, photographic tests, micrometric measurements, trigonometric calculations, and printed enlargements. The outcoming images are scientific encodings and forms of experimental visualization resulting from trial and error. This article analyzes the reflections around the visual error, where knowledge is constructed 
from the interpretation of the visuality of what is visible and invisible to the eyes.

\section{Key words}

Astrophotography, visual error, Carte du Ciel, celestial photography, National Astronomical Observatory 


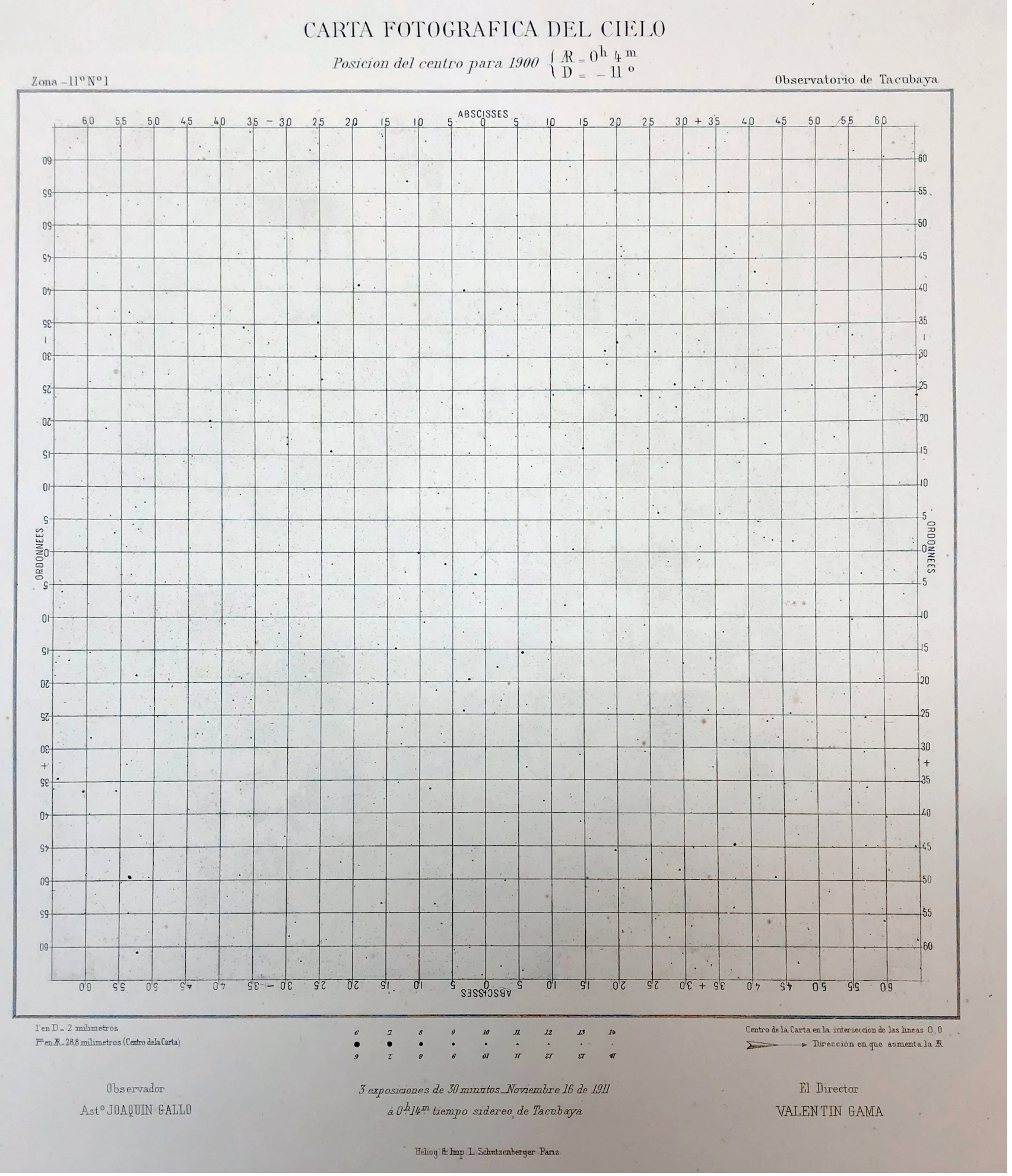

Figura 1. Carta fotográfica del cielo. Zona $-11^{\circ} \mathrm{N}^{0} 1$. Observatorio Astronómico Nacional de Tacubaya, Colección Instituto de Astronomía, UnAm. 
Con la observación directa, casi no es posible medir; incluso con los instrumentos más potentes, el ojo es deslumbrado por lo que aparece en el ocular por innumerables y brillantes partículas de polvo

Ernest Mouchez

El hermoso cielo de México, no obstante su aparente limpidez en el invierno, se halla realmente velado por una nube de polvo casi constante que sin duda debe ejercer alguna influencia en nuestras placas fotográficas y que es, por lo mismo, objeto de nuestro estudio Ángel Anguiano ${ }^{2}$

UNA CARTA FOTOGRÁFICA DEL CIELO TIENE LA APARIENCIA DE UNA HOJA DE CUADERNO cuadriculado repleta de pequeños puntitos de distintos grosores, todos diminutos. El cuadrado que contiene las estrellas está delimitado por mediciones de coordenadas de abscisas y ordenadas. Se trata de un mapa para registrar la posición de las estrellas a través de tres exposiciones fotográficas de 30 minutos cada una, tomadas el 16 de noviembre de 1911; consiste en una impresión de la carta núm. 1 de la zona $-11^{\circ}$, designada como una de las zonas de trabajo para el Observatorio de Tacubaya. Esta carta forma parte de las 1260 placas tomadas por los astrónomos mexicanos como parte del proyecto internacional de la Carte du Ciel para registrar la posición de las estrellas del cielo a través de la fotografía.

La Carte du Ciel fue ideada por David Gill, director del Observatorio de Cabo de Buena Esperanza, y Ernest Mouchez, director del Observatorio de París, a finales del siglo xIx. La intención era obtener un mapa fotográfico de toda la bóveda celeste. Como ya lo señaló Jérôme Lamy, se implementó el uso de una tecnología entonces reciente - la fotografía- a una práctica de la astronomía tradicional, un inventario del cielo. ${ }^{3}$ El pro-

\footnotetext{
1 Ernest Mouchez, La photographie astronomique à l'Observatoire de Paris et la Carte du ciel [traducción de la autora], 54.

2 Ángel Anguiano, Anuario del Observatorio Astronómico Nacional para el año de 1896, 128.

3 Véase Jérôme Lamy, "Adjusting Astronomical Practices: 'The Carte du Ciel', the Demo-
} 
yecto requirió de la colaboración de dieciocho observatorios alrededor del mundo coordinados por Gill y Mouchez. El Observatorio Astronómico Nacional de Tacubaya participó en el proyecto desde 1887 y lo determinó concluido en 1939.

Los estudios en torno a la Carta del Cielo se han enfocado en las relaciones institucionales y los intercambios internacionales, así como en la organización y la estandarización de la práctica astronómica. ${ }^{4}$ Incluso existen proyectos de recuperación de los datos recabados en las placas para su comparación con las posiciones actuales de las estrellas. ${ }^{5}$ En la historia de la astronomía mexicana el capítulo de la Carta del Cielo ha sido reconocido como un paso hacia la modernización de la práctica, pues implicó la adquisición de instrumentos y la interacción con los observatorios involucrados. ${ }^{6}$ Según el astrónomo e historiador Marco Arturo Moreno Corral, gracias a este proyecto se instaló el primer laboratorio fotográfico profesional dedicado a la investigación científica. ${ }^{7}$ Tanto para Moreno Corral como para Jorge Bartolucci, la escasez de recursos humanos, técnicos y financieros provocó que el proyecto se convirtiera en una carga para el Observatorio de Tacubaya y acabó por frenar el avance de la astronomía mexicana durante las primeras décadas del siglo $\mathrm{xx} .{ }^{8}$

Un episodio repetido en la historiografía es que el telescopio utilizado para el proyecto parecía tener un error, pues tras revisar las placas las mediciones no correspondían. Más tarde fue corregido y los trabajos pudieron rea-

cratic Rules and the Circulation of Opinions at the End of the 19 $19^{\text {th }}$ Century", 195.

4 Cfr. Lamy (dir.), La Carte du Ciel. Histoire et actualité d'un project scientifique international; lleana Chinnici, La carte du ciel: Correspondence inédite conservée dans les archives de l'Observatoire de Paris; Lamy, "Adjusting Astronomical Practices: 'The Carte du Ciel"; Lamy, "The Role of the Conferences and the Bulletin in the Modification of the Practices of the Carte du Ciel project at the End of the Nineteenth Century".

5 Cfr. Lasko M. Laskov y Milcho Tsvetkov, "Data Extraction from Carte du Ciel Triple Images".

6 Véase Jorge Bartolucci, La modernización de la ciencia en México. El caso de los astrónomos, 67.

7 Cfr. Marco Arturo Moreno Corral "Astrofotografía en el México del siglo xIX".

8 Bartolucci, La modernización de la ciencia en México, 67. 
lizarse sin mayor problema. ${ }^{9}$ Este artículo ahondará en los procesos de producción de las placas y en la identificación de ese error. La condición visual de las fotografías de las estrellas es, fundamentalmente, una construcción científica: un código producto de un proceso complejo que integra protocolos de observación, tomas fotográficas y mediciones micrométricas. La producción del proyecto internacional de la Carte du Ciel sirve como marco de referencia desde donde cuestionar y reflexionar en torno a la práctica fotográfica astronómica mexicana de inicios del siglo xx.

Desde mediados del siglo xIx la fotografía se utilizó como herramienta de apoyo para distintas ciencias. Aunque se lograron imágenes del cielo desde los primeros años, la astronomía se benefició de la fotografía una vez que se alcanzó una mayor sensibilidad en las emulsiones fotográficas. El uso del colodión húmedo como aglutinante requería que durante los tiempos de toma y revelado la emulsión permaneciera húmeda. La introducción de la gelatina de bromuro sustituyó al colodión y ello permitía trabajar en seco. En la década de 1880 la industria fotográfica comenzó la comercialización de placas preparadas que ofrecían rapidez y mayor sensibilidad, aunque fue sólo a principios del siglo xx cuando se establecieron velocidades de película confiables; ${ }^{10}$ al modificar los tiempos de exposición un objeto muy tenue o lejano podía quedar registrado sobre la placa. Los trabajos realizados en 1885 por los hermanos Paul y Prosper Henry, astrónomos del Observatorio de París, siguieron "las tradiciones de los grandes astrónomos de los siglos pasados, quienes estuvieron involucrados en la construcción de sus instrumentos"11 en su taller de Montrouge y dedicaron su tiempo a estudiar el tamaño y el pulido de las placas y construyeron un objetivo con $33 \mathrm{~cm}$ de apertura. Con esta calidad óptica lumínica lograron captar por primera vez objetos invisibles para el ojo; por ejemplo, después de tres

\footnotetext{
9 Existen sólo dos investigaciones sobre la Carta del Cielo en México; cfr. Ángel Mireles Estrada, "La Carta del Cielo: un capítulo internacional de la ciencia mexicana" y Enrique Téllez Fabiani, "Observatorio Astronómico Nacional: trabajos fotográficos y geográficos bajo la dirección de Ángel Anguiano (1877-1899)".

10 Kelly Wilder, Photography and Science, 68.

11 Mouchez, "La Photographie Astronomique à l'Observatoire de Paris", 4.
} 
CAR'TA FOTOGRAFICA DEL CIELO

Posicion del centro para $1900\left\{\begin{array}{l}R=0^{\mathrm{h}} 4^{\mathrm{m}} \\ \mathrm{D}=-11^{\circ}\end{array}\right.$

observatorio de Tacubaya

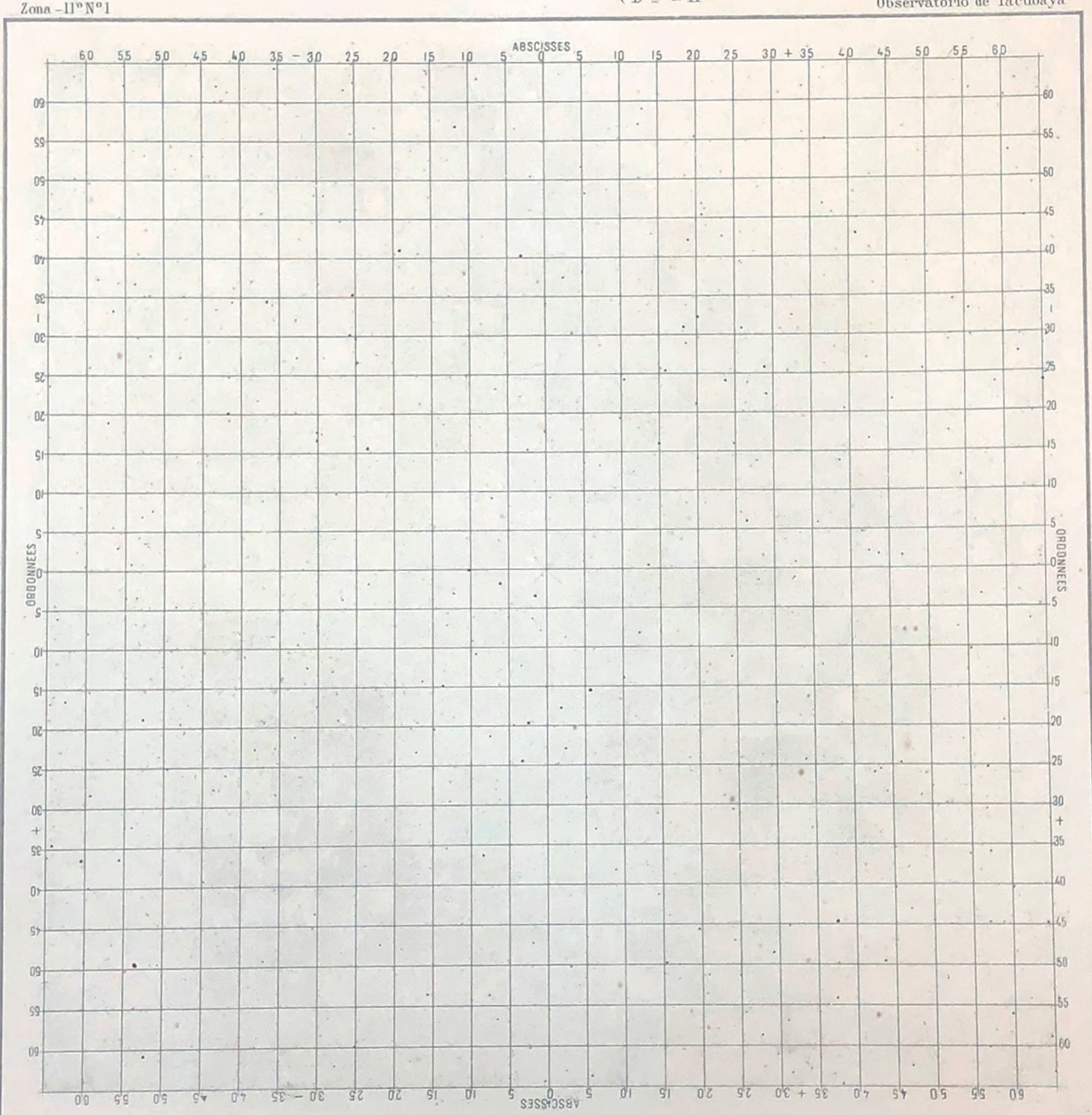

Ies D. 2 milimetron

PeR.28.8 milumetros (Cutro deh Carta)

Observador

Ast ${ }^{\circ}$ JOAQUTN GALLD

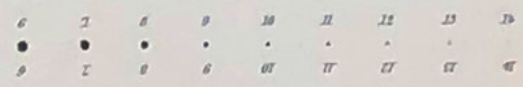

3 exposicanes de 30 mmutos. Noviembre 16 de 1911

$a^{b} b^{m}$ tiempo sidereo de Tacubaya

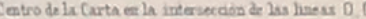

$\Longrightarrow$ Tirecoion ca quo somenta in $D$

Bl Director

VALENTIN GAMA

telog 1 Imp 2 Schatumberger Pans

Figura 2. Carta fotográfica del cielo. Zona $-11^{\circ} \mathrm{N}^{\circ} 1$. Posición del centro para 1900

Observador: Joaquín Gallo. Tres exposiciones de 30 minutos. 16 de noviembre de 1911 
horas de exposición la nebulosa Maia se visualizó en la placa fotográfica;12 la nebulosa en espiral se descubrió junto a una de las estrellas más brillantes de las Pléyades. Al respecto expresó Ernest Mouchez: “¡Ya estamos más allá de los límites de visibilidad para las mejores gafas bajo el cielo de París!"13

¿Qué implica hacer visible fotográficamente aquello que se encuentra tan lejano que no es perceptible a la vista? Ensayar la mirada como ejercicio de instrucción, mirar repetidas veces, parpadear y volver a mirar; el ojo debe prepararse para identificar lo registrado. El ojo debe acostumbrarse y entrenarse para definir las figuras y construir una visualidad astronómica. El astrónomo debe pasar por un proceso de sensibilización, de entendimiento de lo que se ve, de interpretación de lo que se cree ver y de aprendizaje sobre cómo dar sentido mediante los referentes.

Los dispositivos como el telescopio fotográfico permiten multiplicar infinitamente la eficiencia de los órganos del cuerpo y ampliar sus capacidades. Como creía Mouchez, la tecnología lograría "eximirlo de pedirles esfuerzos excesivos; lo alivian, lo liberan cada vez más de la dura servidumbre del trabajo material". ${ }^{14}$ Así, los astrónomos podrían observar y estudiar más allá de los límites de lo visible.

Si la fotografía trabaja en conjunto con el telescopio y mediante instrumentos fotográficos hace visibles más estrellas que con artefactos ópticos, surgen preguntas fundamentales que incitan una reflexión más profunda: ¿cómo visualizar algo que es invisible a los ojos?, ¿cuáles son los procesos que hacen visible y dan sentido a una imagen para que luego se convierta en conocimiento? Éstas son algunas de las preguntas que guiaron el presente texto.

\footnotetext{
12 Prosper Henry y Paul Henry, "On Photographs of a New Nebula in the Pleiades, and of Saturn", 98.

13 Mouchez, "La Photographie Astronomique", 4.

14 Mouchez, "La Photographie Astronomique", 69.
} 


\section{Formación de la carta celeste por medio de la fotografía}

Durante el primer Congreso Astro-fotográfico Internacional, celebrado entre el 16 y el 25 de abril de 1887 en París, Mouchez anunció la construcción de la Carte du Ciel. ${ }^{15} \mathrm{~A}$ la reunión asistieron más de cincuenta extranjeros y una veintena de franceses, en su mayoría astrónomos y socios de academias de ciencias. Se estableció una Comisión Internacional Permanente con once miembros a los que se unieron más tarde los directores de los observatorios participantes. A la par se formó un comité con nueve integrantes, responsable de garantizar la ejecución de sus decisiones, centralizar la información y mantener en comunicación a los asociados a través de la publicación del boletín. ${ }^{16}$

A México se le consideró después de que Ángel Anguiano, director del Observatorio de Tacubaya, enviara en 1887 al Observatorio de París una fotografía de la Luna tomada por Teodoro Quintana. La respuesta de Mouchez fue halagadora y reconoció que ignoraba la producción fotográfica de la astronomía mexicana. ${ }^{17}$ Con ello recibió la invitación a participar en el proyecto, según narra Anguiano en el Anuario del Observatorio de Tacubaya, publicado en 1888 .

La organización de las actividades formó parte de la transformación de los observatorios en fábricas científicas. A partir del modelo industrial el trabajo se dividió, se definieron las tareas y se estandarizaron los instrumentos. ${ }^{18}$ Jérôme Lamy identificó cuatro operaciones distintas para la Carte du Ciel: 1) medir las posiciones de las estrellas guía con un instrumento meridiano;

15 Cfr. Congrés Astrophotographic International tenu à l'Observatoire de Paris pour le levé de la Carte du ciel. Paris, 1887. Citado en Ileana Chinnici, La Carte du ciel: Correspondence inédite conservée dans les archives de l'Observatoire de Paris, 6.

16 Mouchez, "La Photographie Astronomique", 629.

17 "Todos los detalles han salido con una claridad perfecta, que prueba no solamente la habilidad del observador, sino también la pureza de vuestro cielo y la bondad de vuestro objetivo." Véase Anguiano, "Formación de la Carta Celeste por medio de la fotografía", en Anuario del Observatorio Astronómico Nacional de Tacubaya para el año de 1889, 71.

18 Lamy, "The Role of the Conferences", 121. 
2) tomar las fotografías celestes y procesarlas; 3) determinar las posiciones de las estrellas en las placas, y 4) reducir las mediciones de las posiciones de las estrellas mediante cálculos para obtener el valor en coordenadas. ${ }^{19}$

El mapa fotográfico celeste registraría las estrellas de hasta la $14^{\mathrm{a}}$ magnitud, y a la par se realizaría un catálogo astrofotográfico con las coordenadas de las estrellas de hasta la $11^{a}$ magnitud de la bóveda celeste. ${ }^{20}$ Estos límites del brillo aparente de las estrellas tienen que ver con los límites técnicos que ofrecía el telescopio probado y avalado por el Observatorio de París.

En la primera reunión se estandarizó el uso del telescopio refractor ${ }^{21}$ con las características probadas por los hermanos Henry del Observatorio de París en sus experimentos de 1885: ${ }^{22}$ un telescopio fotográfico con un objetivo de 33 $\mathrm{cm}$ de diámetro con una distancia focal de $3.43 \mathrm{~m}$, de manera que un minuto de la bóveda celeste corresponda a $1 \mathrm{~mm}$ en la placa. ${ }^{23} \mathrm{La}$ relación focal entre la distancia y la apertura es $\mathrm{f} / 10$, lo que indica que requiere de tiempos de exposición muy largos. Los primeros acuerdos estipulaban que las exposiciones serían de 40 minutos, para la carta, mientras que para el catálogo serían de

19 Véanse Lamy, "The Role of the Conferences", 120; Lamy, "La carte du ciel et l'ajustement des pratiques (Fin XIX - Debut $x x^{\mathrm{e}}$ siècle)", 47-50.

20 La magnitud aparente es la intensidad de brillo de un astro observado desde la Tierra. El límite visual de la percepción humana es de la $6^{a}$ magnitud; el máximo brillo de Plutón, que no se ve sin un telescopio, corresponde a la $14^{\mathrm{a}}$ magnitud.

21 El telescopio refractor utiliza el mismo principio óptico que los objetivos fotográficos: el rayo de luz atraviesa la lente y converge sobre un punto del plano focal. Para corregir las aberraciones cromáticas causadas por las diferentes longitudes de onda de la luz, se ocupan dos tipos de lentes de dispersión: una lente convexa fabricada con vidrio Crown y una lente cóncava hecha de un vidrio Flint. En cambio, un telescopio reflector puede ser mucho más luminoso, puesto que la abertura puede lograrse en mayores dimensiones que en el refractor, e incluso no se ve afectado por las aberraciones cromáticas. Sin embargo, los integrantes del primer congreso estuvieron de acuerdo en servirse de un refractor, al ser mucho más sencillo de utilizar y no exigir "tanta habilidad en el observador". Véase Anguiano, "Formación de la Carta Celeste por medio de la fotografía", 97.

22 Mouchez, La photographie astronomique, 31, cit. en Anguiano, "Formación de la Carta Celeste por medio de la fotografía", 103. El telescopio construido por los hermanos Henry funcionó de modelo para la ejecución del proyecto. Una ilustración del telescopio instalado en París y la imagen obtenida de las Pléyades en 1885 se puede encontrar en: http://www.klima-luft.de/steinicke/ngcic/persons/henrys.htm.

23 Mouchez, La photographie astronomique, 79. 
cinco minutos. Sin embargo, las distintas experiencias de los astrónomos confirmaron que cada observatorio debía determinar los tiempos de acuerdo con las condiciones atmosféricas del momento de la toma.

El telescopio consta de dos anteojos paralelos: el fotográfico y el que sirve de guía para el observador. El telescopio fotográfico que se instaló en Tacubaya, y actualmente se ubica en Tonanzintla, tiene una montura ecuatorial que permite el movimiento en combinación de dos ejes perpendiculares de movimiento horizontal, conocido como declinación, así como uno de movimiento vertical, también llamado "de ascensión recta". Ángel Anguiano consultó opciones y presupuestos, y se decidió por la casa constructora irlandesa Grubb. En 1890 se terminó de instalar y se comenzaron las pruebas. ${ }^{24}$

La comisión se reunió nuevamente en los años 1889, 1891, 1896, 1900 y $1909 .{ }^{25}$ Las resoluciones de 1889 definieron la forma y el tamaño de las placas: serían de $16 \mathrm{~cm}$ por lado y cada observatorio podría elegir el fabricante. En México se utilizaron primero las placas francesas Lumière y posteriormente se cambiaron por las Kodak. ${ }^{26}$ La parte útil de la placa se reduce a un cuadrado de $13 \mathrm{~cm}$, porque el campo útil del objetivo fotográfico es de aproximadamente $1^{\circ}$ desde el centro y ello provoca una aberración en los márgenes de la placa. ${ }^{27}$

En el congreso de 1891 se establecieron los procedimientos de observación, la montura de la placa en el telescopio y las operaciones para elegir la estrella-guía. ${ }^{28}$ También se acordó crear una comisión para definir demo-

24 El diseño de Grubb también fue utilizado por siete observatorios participantes del proyecto. Véase P. A. Wayman, "The Grubb Astrographic Telescopes, 1887-1896", 139142. Una ilustración del diseño está disponible en https://academic.oup.com/view-large/ figure/94072413/41-5-5.16-fig002.gif. En un documento de difusión sobre la historia del Observatorio Astronómico Nacional se observan detalles del telescopio refractor instalado en Tacubaya entre las páginas 157-172; está disponible en https://www.astroscu. unam.mx/IA/images/UNA\%20HISTORIA\%20GRAFICA\%20del\%20OAN.pdf.

25 Chinnici, "La Carte du Ciel, genèse, déroulement et issues", 25.

26 Cfr. Joaquín Gallo, "Solicitud de placas fotográficas especiales de 16 × 16 centímetros".

27 Chinnici, La carte du ciel, 7.

28 Véase Anguiano, Anuario del Observatorio Astronómico de Tacubaya, 97. 


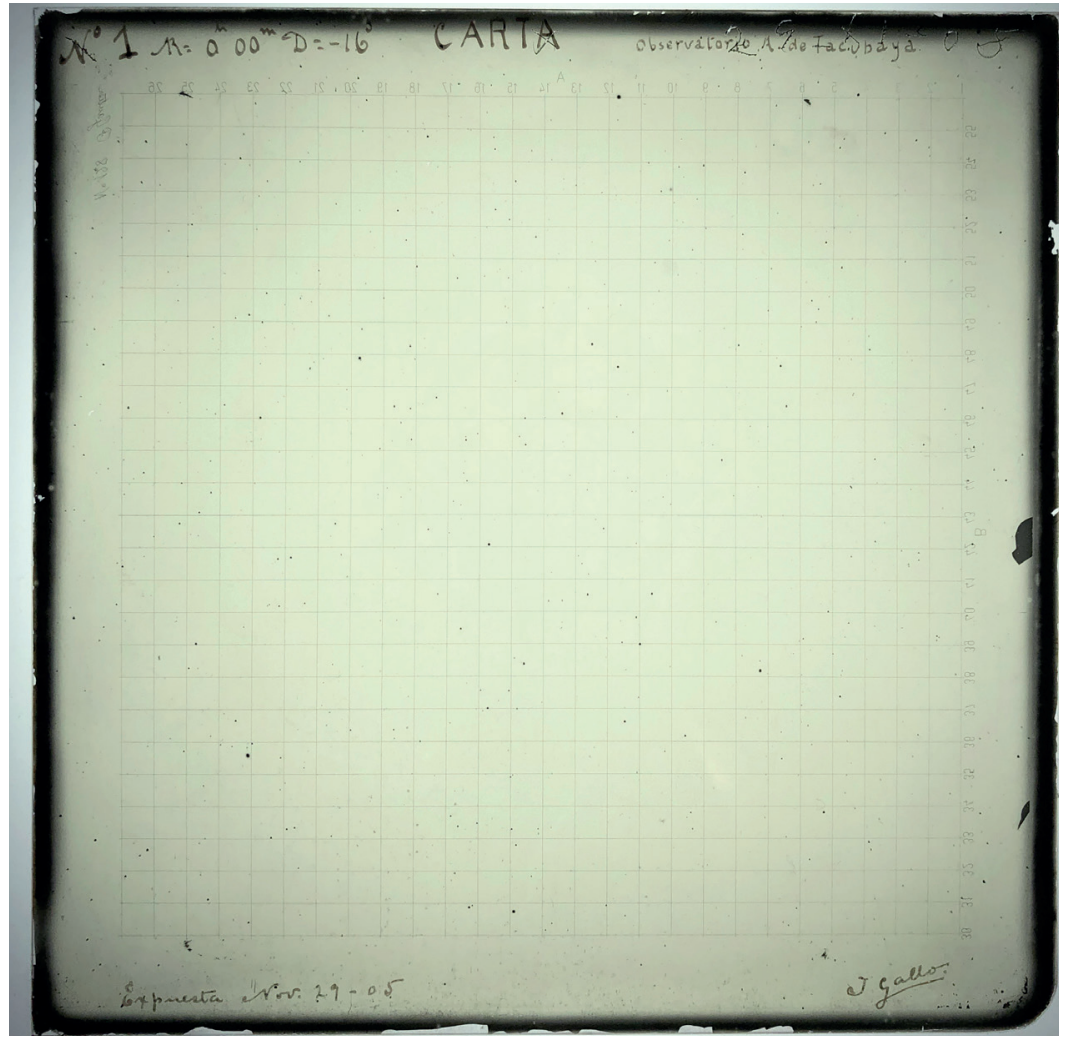

Figura 3. Joaquín Gallo. Carta del Cielo. Zona -16º No 1. 29 de noviembre de 1905. Observatorio Astronómico Nacional de Tacubaya,

Biblioteca "Guillermo Haro" del Instituto de Astronomía, UNAM.

cráticamente que se realizarían dos series de placas: la primera para la carta fotográfica y la segunda para el catálogo astrofotográfico. Para la carta se harían tres exposiciones por placa formando un triángulo equilátero para asegurarse de la impresión de todas las estrellas y no evitar la confusión con impurezas accidentales. ${ }^{29}$

Por último se confirmó la participación de 18 observatorios y se dividieron las zonas a fotografiar. El fragmento asignado a Tacubaya era el corres-

29 Véase Lamy, "La carte du ciel et l'ajustement des pratiques", 55. 


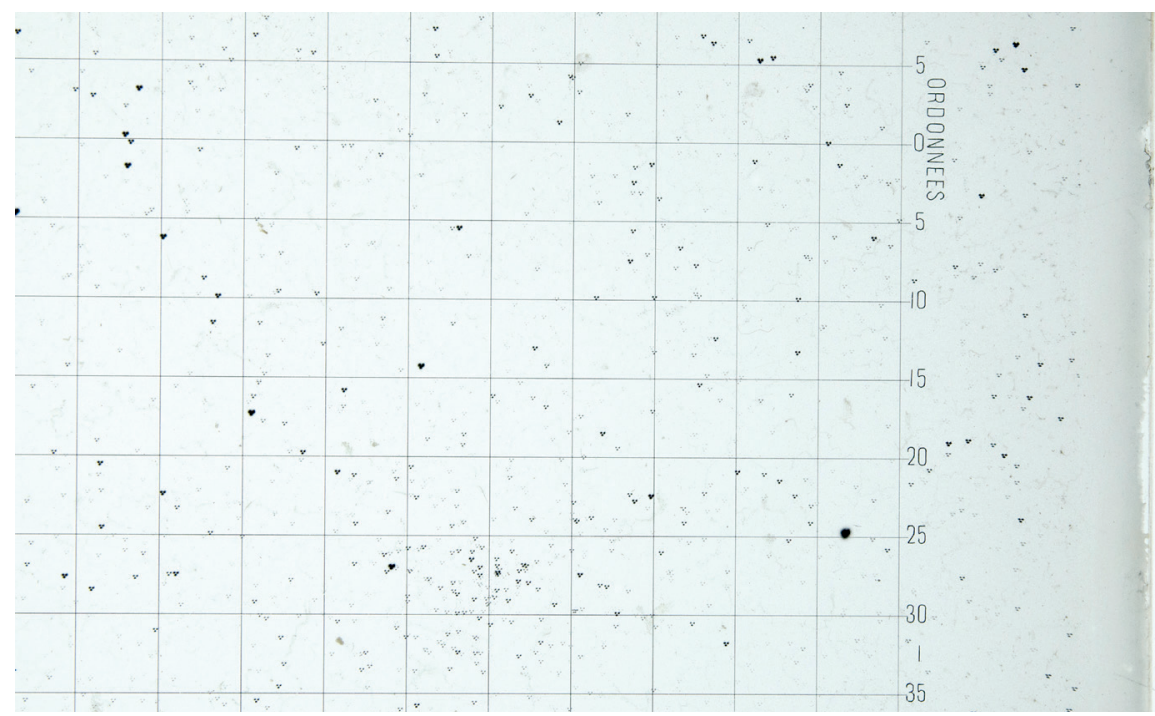

Figura 4. Detalle de asterisms o triángulos estelares. Zona $-15^{\circ} \mathrm{N}^{\circ} 55^{\circ}$.T.S. 1h $16 \mathrm{~m}$ Exm. 31 de enero de 1908. Observatorio Astronómico Nacional de Tacubaya, Biblioteca "Guillermo Haro" del Instituto de Astronomía, unAm.

pondiente a las zonas de -10 a -16 grados de declinación, en total, se lograron registrar 312,000 estrellas en 1,259 placas. $^{30}$

Para efectos de conservación del material el comité propuso imprimirlo por medio del fotograbado, de modo que pudiera servir a las generaciones posteriores. Las impresiones se mandaron a hacer a la casa L. Schützenberger en París, pues en México no se producía esta técnica fotomecánica con la calidad requerida. ${ }^{31}$

En el boletín publicado por el Comité Internacional Permanente se desarrollaron los procesos, los errores y problemáticas más comunes y su eventual método para evitarlos o, en su caso, corregirlos. Por ejemplo, en el boletín publicado en 1895 explicaron el método para evitar la acumulación de polvo sobre la red por medio de la limpieza de la placa con una brocha, para así

30 Véase Urban, S. E., et al. "The AC 2000: The Astrographic Catalogue on the System Defined by the Hipparcos Catalogue”, 1212-1223.

31 Véase Archivo AHUnam foAn, caja 14, exp. 127. 
evitar las estrellas falsas. Esta publicación se presentó como un espacio de información y discusión destinado a producir un acuerdo entre los astrónomos. ${ }^{32} \mathrm{El}$ intercambio de cuestiones técnicas era tema común en la correspondencia entre los directores del comité y de los otros observatorios participantes: se pedían consejos para la preparación de la placa y de los químicos y aclaraban dudas en torno a los procesos matemáticos de medición y reducción. ${ }^{33}$ Otro de los temas discutidos fue la aplicación de una cuadrícula sobre la placa para que las mediciones se realizaran directamente en la placa y no sobre las ampliaciones al papel. El boletín contó con una sección que reproducía la correspondencia para que todos los asociados estuvieran enterados de las pruebas realizadas y los métodos más confiables a seguir.

Una vez expuesta y revelada la placa se obtenía una imagen abstracta del cielo. Los pequeños triángulos equiláteros formados por tres puntos dispersos en el plano cuadriculado funcionan como el campo epistémico de la imagen. Es decir, cada punto se convierte en un valor en relación a los ejes del plano. Por tanto, el valor de la foto no reside en lo figurativo ni en lo icónico, sino en la posición del registro visual en las coordenadas marcadas en la placa.

El uso de la fotografía como herramienta de medición se remonta a los primeros usos científicos del medio. En astronomía se intentó aplicar en los tránsitos de Venus de 1874 y 1882, pero las emulsiones de colodión producidas por cada astrónomo no permitieron estandarizar los resultados y obtener los valores de distancias precisas. El uso de la gelatina de bromuro posibilitó, entre otras cosas, aplicar métodos de observación medible directamente sobre la placa fotográfica. ${ }^{34}$ La fotografía representa el objeto específico en un momento y en un lugar específicos, siempre y cuando el observador mantenga el control sobre las emulsiones y sus reacciones a los tiempos de exposición. En Tacubaya Guillermo B. y Puga, encargado del Departamento Astro Fotográfico desde 1892, realizó distintos experimentos expositivos con 14

\footnotetext{
32 Véase Lamy, "The Role of the Conferences", 122.

33 Cfr. Chinnici, La carte du ciel: Correspondence inédite conservée dans les archives de l'Observatoire de Paris, 1999.

34 Wilder, Photography and Science, 18-50.
} 
marcas de placas para identificar la más estable con mejores tiempos de exposición y eligió la marca Lumière, importada de Francia.

La medida de las estrellas en las placas se traduce a una coordenada lineal a través de un microscopio de precisión o micrómetro. ${ }^{35}$ La distancia de la estrella a la cuadrícula en la placa sería traducida en coordenada de posición: expresada en número entero y fracciones de minutos y segundos. La cantidad de las estrellas por medir y las múltiples operaciones matemáticas que se debían desarrollar llevó a Mouchez a proponer un taller de mujeres medidoras de las placas desde $1886 .{ }^{36}$ Un grupo de mujeres medidoras ${ }^{37}$ determinaban la posición de cada estrella midiendo "la distancia de la estrella a la raya inmediata anterior a la red". ${ }^{38}$ Las mediciones sobre la placa para obtener coordenadas ecuatoriales son el acto epistémico de la imagen desde donde se construye su visualidad. La traducción del registro

35 Diseñado por Gautier. Véase Chinnici, La carte du ciel: Correspondence inédite, 8. En México se optó por comprar el microscopio producido por Troughton \& Simm de Londres. En el siguiente documento sobre los instrumentos del Observatorio Astronómico se aprecian dos microscopios de precisión para medir las placas en las páginas 115, 117 y 119: https://www. astroscu.unam.mx/IA/images/UNA\%20HISTORIA\%20GRAFICA\%20del\%20OAN.pdf.

36 Lamy, "La Carte du Ciel et la création du 'Bureau des Dames', 105.

37 Como parte de la división del trabajo, se creó un departamento de medición y en varios observatorios participantes contrataron a mujeres para realizar las mediciones (Lyon, París, Toulouse, Greenwich). Edward C. Pickering del Observatorio de Harvard fue el primero en contratar mujeres, desde 1885. Jean Mascart, astrónomo del Observatorio de Lyon, asoció el trabajo femenino con las aptitudes femeninas de precisión asociadas a la atención, la calma y la disciplina, además de considerarse un trabajo "menor" con un sueldo precario por ser repetitivo y mecánico. Jerome Lamy analiza el caso de Toulouse y da cuenta de la situación laboral de las mujeres. Véase Lamy, "La Carte du Ciel et la création du 'Bureau des Dames'”, 101-120. En México hace falta un estudio sobre las mujeres medidoras. En mi búsqueda en el Fondo del Observatorio Astronómico Nacional aparecieron los nombres de las siguientes mujeres como parte de los miembros del Observatorio de Tacubaya al firmar acuse de recibo de diversos comunicados internos: Rosario Rodríguez Rey (pariente del ingeniero y astrónomo del observatorio Francisco Rodríguez Rey), Dolores Moncada (pariente del ingeniero y astrónomo del observatorio Manuel Moncada), Beatriz Arellana, María García y Josefina (apellido ilegible). Caja 139, exp. 970, fs. 124, 137, 146. Cabe destacar que estas mujeres trabajaron durante la década de 1920 bajo la dirección de Joaquín Gallo.

38 Autor desconocido, "Medida de placas", Documento mecanuscrito sin fecha. AHUNAM FOAN caja 14, exp. 124. 
fotográfico en coordenada ocurre en este lugar del plano. ${ }^{39}$ Este proceso llevó muchos años; como referencia para dar una idea del trabajo que implica la medición, Anguiano hace mención de los resultados obtenidos por la Universidad de Oxford: 37,404 estrellas medidas en 136 placas..$^{40}$

Por último, un calculador reducía las mediciones a partir del método trigonométrico ideado por Turner en $1893 .{ }^{41}$ Las fórmulas relacionaban las coordenadas rectangulares de las placas con la ascensión recta y la declinación a través de la seis "constantes de placa", determinadas a partir de estrellas de referencia de posición conocida. ${ }^{42}$ Para 1893 tan sólo se contaba con un calculador en el Observatorio de Tacubaya, provocando que el trabajo acumulara datos sin orden. ${ }^{43}$

\section{Ensayo y error}

El análisis de la práctica fotográfica astronómica a través de los ensayos y reflexiones de los astrónomos del Observatorio de Tacubaya conservados en el Fondo del Observatorio Astronómico Nacional, resguardado en el Archivo Histórico de la UNAM, nos obliga a alejarnos para crear un espacio de reflexión que devele los procesos de producción que permiten cuestionar la autenticidad, los alcances y la precisión que tanto se le pregonó a la técnica. ${ }^{44} \mathrm{En}$ el fondo consultado tan sólo se conservan fragmentos de textos, algunos manuscritos y mecanuscritos que especifican los métodos de medida y reducción de las placas.

39 El uso de la fotografía para cartografiar y medir distancias también fue una de las aplicaciones científicas a principios de siglo xx. Véase Otto Lemberg, "La fotogrametría terrestre y aérea. Su aplicación en la formación de planos técnicos y cartas geográficas", en Memorias de la Sociedad Científica Antonio Alzate, vol. 50, 1-23 (1929).

40 Anguiano, Anuario del Observatorio Astronómico Nacional de Tacubaya para el año de 1897, 234.

41 Autor desconocido, "Reducción de las placas", AHUnAm FOAN, caja 14, exp. 124.

42 Fras Derek Jones, "The Scientific Value of the Carte du Ciel", 5.16-5.20. Las ilustraciones 3 y 4 son un ejemplo del proceso de medición de placas.

43 Cfr. Anguiano, Anuario del Observatorio Astronómico Nacional de Tacubaya para el año de 1894.

44 Anguiano, "Formación de la Carta Celeste", 67. 
En los escritos existen indicaciones para prevenir o corregir los errores provenientes de las mediciones y cálculos. ${ }^{45}$ Vale la pena rescatar aquí una reflexión que sobresale de los argumentos: después de comparar dos placas del mismo centro con resultados distintos en la reducción, el astrónomo anónimo que redactó el informe se preguntó: la anomalía "¿depende la diferencia señalada de circunstancias inherentes a la placa o al observador y clase de instrumento?; ¿es igual en las estrellas del centro y en las de los bordes, o en otros términos: influye la deformación que experimentan las imágenes cerca de las esquinas?; ¿influye el cansancio, la fatiga del ojo en el curso del trabajo? No tenemos datos para contestar a estas preguntas", ${ }^{46}$ concluyó. El documento no tiene fecha ni firma; sin embargo, las preguntas del astrónomo pueden ser consideradas como indicio del reconocimiento de un error cuya causa está por descubrirse.

En 1891 el Observatorio de Tacubaya envió nueve placas de prueba al Observatorio de Oxford para su visto bueno, pero llegaron rotas y no se pudieron verificar. Otras más se enviaron para la revisión por el Comité en la Conferencia de ese año en París; los resultados se compararon con el resto de los observatorios y no se identificaron errores. ${ }^{47}$ Sin embargo, en las placas enviadas al Observatorio de París en 1897 se identificaron errores al medirlas con precisión. ${ }^{48}$ Ya que la placa registra aquello que nuestros ojos no logran definir, ¿cómo identificar el error en las placas si lo que se visualiza está más allá de lo que vemos a simple vista?

Para Clement Chéroux el error fotográfico tiene tres causas: alguna falla técnica en el aparato, una mala manipulación por parte del fotógrafo y los

\footnotetext{
45 "Indicaciones a los calculadores", AhUnam foan caja 14, exp. 124.

46 "Medida de placas", AHUnAm FOAN caja14, exp. 124 f.2. Si seguimos las reflexiones de Clement Chéroux sobre el error fotográfico, estas preguntas son el testimonio de su propia ceguera.

47 Anguiano, Anuario del Observatorio Astronómico de Tacubaya para el año de 1893, 93.

48 Véanse Ángel Mireles Estrada, La Carta del Cielo: un capítulo internacional de la ciencia mexicana", 28; Marco Arturo Moreno Corral, "Telescopios que han influido en el desarrollo de la astronomía y la astrofísica en México”, 51-62.
} 
diversos accidentes provenientes del tema a fotografiar..$^{49} \mathrm{La}$ complejidad del proceso de toma, medición y reducción de las placas implica también que el error puede ser ocasionado por cualquiera de las tres causas en cualquiera de las tres operaciones. Chéroux recuerda las palabras de Bernard Lamarche-Vadel: "La fotografía ofrece un punto de vista sobre la ceguera de su espectador", ${ }^{50}$ para demostrar el modelo teórico que permite comprender el funcionamiento de la mirada: "ese desfase absoluto entre lo que muestra la imagen y el contenido que le es atribuido." 51

Al intentar identificar el error en las placas de la Carta del Cielo el funcionamiento de la mirada se devela en el conjunto de reflexiones escritas. A simple vista los errores no son fáciles de identificar; la imagen muestra puntos sobre un plano, algunos más grandes, otros más pequeños, puntos que conforman estrellas, puntos que registran el polvo y puntos que designan errores ópticos. La mirada del astrónomo cambia su dirección hacia el registro fotográfico. El observador, que se pensaba sustituido o reemplazado por la placa fotográfica, vuelve a ocupar un lugar en el proceso de experimentación científica necesario para la verificación.

Si el límite de la visión del observador es modificado al interpretar el campo visual registrado en la placa fotográfica, el astrónomo deberá ser capaz de visualizar aquello invisible a sus ojos. Cabe cuestionar el papel que ocupa la visualidad en la construcción del conocimiento. Ésta puede ser entendida como el conjunto de las técnicas sociales e históricas específicas de los mecanismos de visión. El telescopio y la fotografía son mecanismos que hacen visibles objetos específicos que son invisibles para el ojo humano; es necesaria la intervención del astrónomo para que a través de su "juicio de experto" 52 identifique

49 Clement Chéroux, Breve historia del error fotográfico, 41.

50 Cfr. Bernard Lamarche-Vadel, Lignes de mire. Écrits sur la photographie.

51 André Gunthert, "Le complexe de Gradiva”, 120.

52 Lorraine Daston y Peter Galison analizan cómo la objetividad mecánica del siglo xIx buscaba eliminar la intervención del sujeto mientras se confiaba en la neutralidad de la máquina y la transparencia del operador, como un ideal de la disciplina moral de los científicos. En el tercer capítulo de su libro concluyen cómo la ambición de producir una imagen objetiva se complementó mecánicamente con una estrategia que reconoció explícitamente la necesidad 


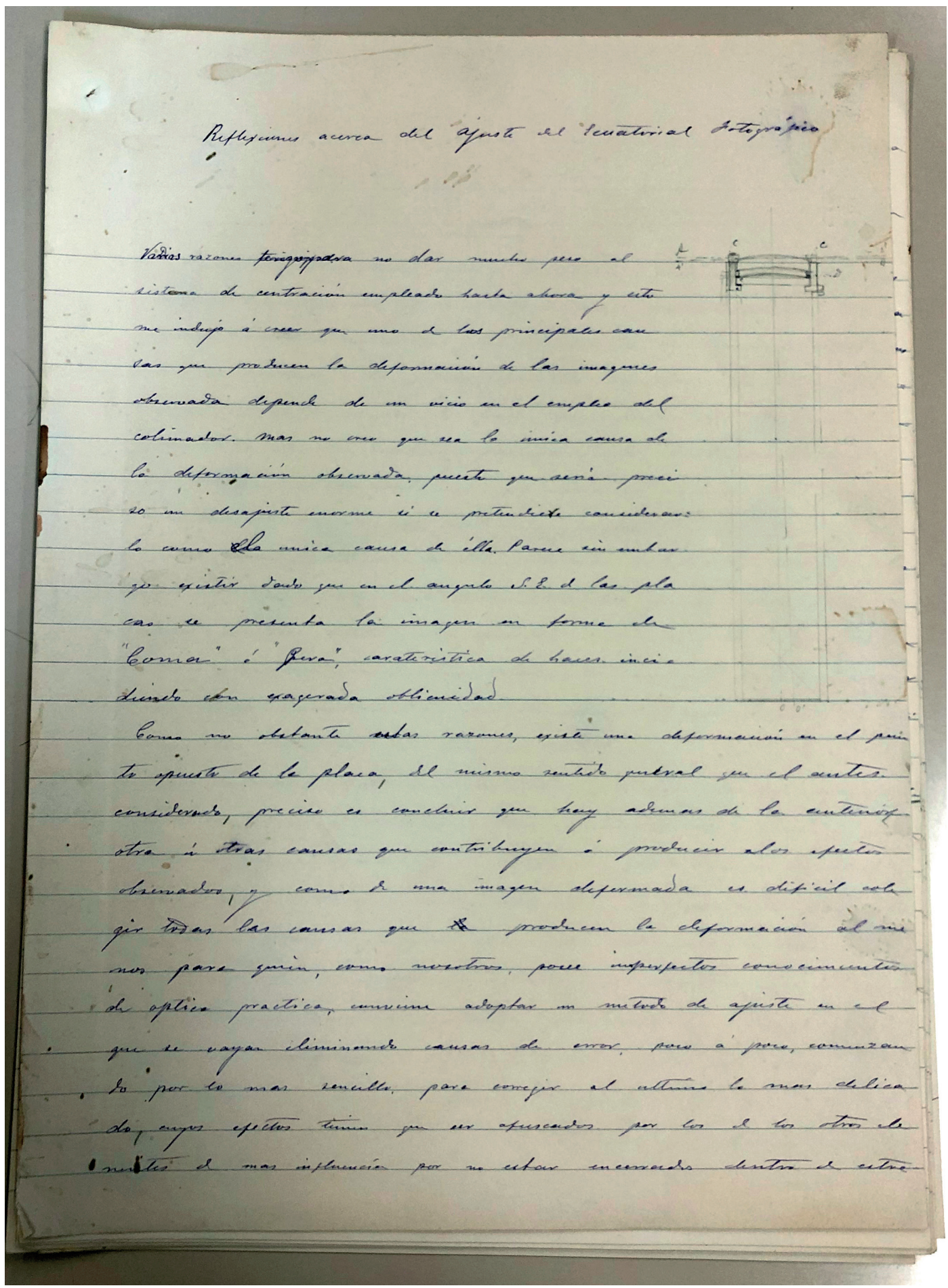

Figura 5. Felipe Valle. Reflexiones acerca del ajuste al Ecuatorial Fotográfico Manuscrito, 1897, exp. 399, caja 39. Observatorio Astronómico Nacional de Tacubaya, Biblioteca "Guillermo Haro" del Instituto de Astronomía, UnAM. 
Nierika 20 - Año 10 - julio-diciembre de 2021

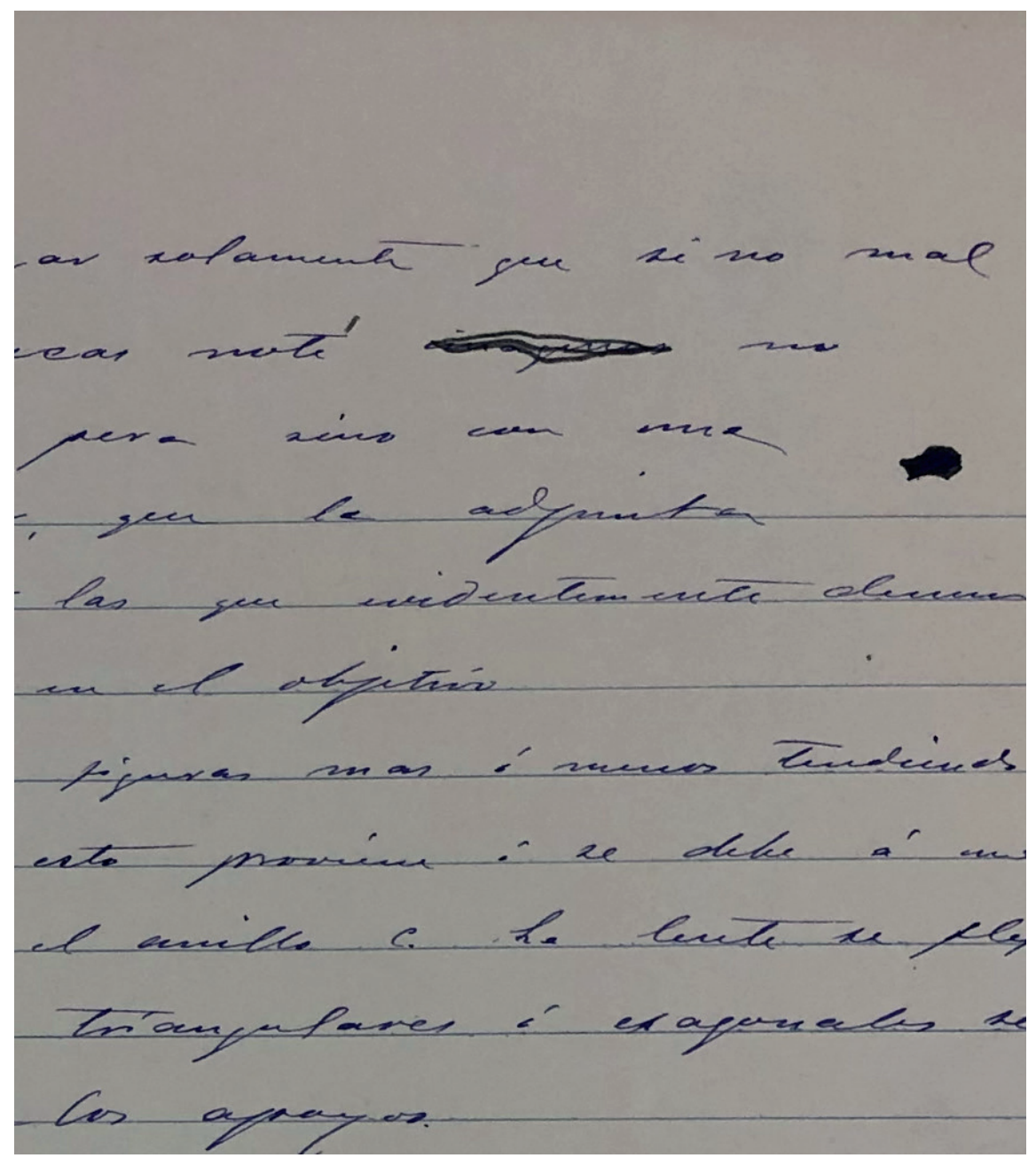

Figura 6. Felipe Valle. Reflexiones acerca del ajuste al Ecuatorial Fotográfico Manuscrito, 1897, exp. 399, caja 39. Observatorio Astronómico Nacional de Tacubaya, Biblioteca "Guillermo Haro" del Instituto de Astronomía, UNAM. 
una placa bien lograda de aquella que contiene errores. Para ello será necesario educar la mirada ${ }^{53}$ para recrear las condiciones de visibilidad.

Anguiano cuestionó la aparición de pequeños puntitos en las placas, la diferenciación de estos puntos producidos por el polvo de aquellas estrellas formadas por tres puntos es en cierta medida un primer paso en pensar desde la visualidad. ${ }^{54}$ Concluyó que las condiciones propias del Observatorio de Tacubaya, la altitud y la contaminación eran la causa de la aparición de las manchas en la imagen. ${ }^{55}$ Sin embargo, no explicó cómo corregir o compensar el error. Es probable que decidiera seguir las recomendaciones del boletín de 1895 .

Al mirar detenidamente las imágenes, Guillermo Beltrán y Puga, encargado del departamento fotográfico, notó desde 1894 algunas irregularidades en las placas: las estrellas de la $11^{a}$ magnitud no aparecían en algunas; su conclusión fue que las placas fotográficas que usaban eran menos sensibles que las anteriores, así que "resolvieron" incrementar el tiempo de exposición y de revelado. ${ }^{56}$ La inquietud de Beltrán y Puga era rebasar el límite de lo visible a través del instrumento y del procedimiento fotográfico cuyo registro visual puede ser casi tan permanente y sensible como se quiera.

Más tarde Beltrán y Puga estudió nuevamente las imágenes y redactó en 1897 la descripción de los defectos y los procedimientos para corregirlos: 1) La deformación de algunas estrellas en las imágenes y 2) las estrellas

de emplear un juicio capacitado para crear y utilizar imágenes. Lorraine Daston y Peter Galison, "The Image of Objectivity", 81-128; véase también Daston y Galison, Objectivity.

53 Joel Snyder analiza el caso de Etienne Jules Marey, quien propone los límites de la visualización y la visibilidad al afirmar que las imágenes de la cronofotografía apelan más a la imaginación que a los sentidos, nos enseñan a observar a la naturaleza con mayor detenimiento; "esta educación del ojo" se enriquece siempre por la experiencia de mirar el movimiento. Véase Joel Snyder, "Visualization and Visibility", 383.

54 Pensar desde la visualidad implica analizar la condición visual del registro fotográfico.

55 Cfr. Anuario del Observatorio Astronómico Nacional de Tacubaya para el año de 1897.

56 Guillermo Beltrán y Puga (firmado por), Tacubaya, 4 de mayo de 1894. AHUNAM FOAN caja 14, exp. 124. 


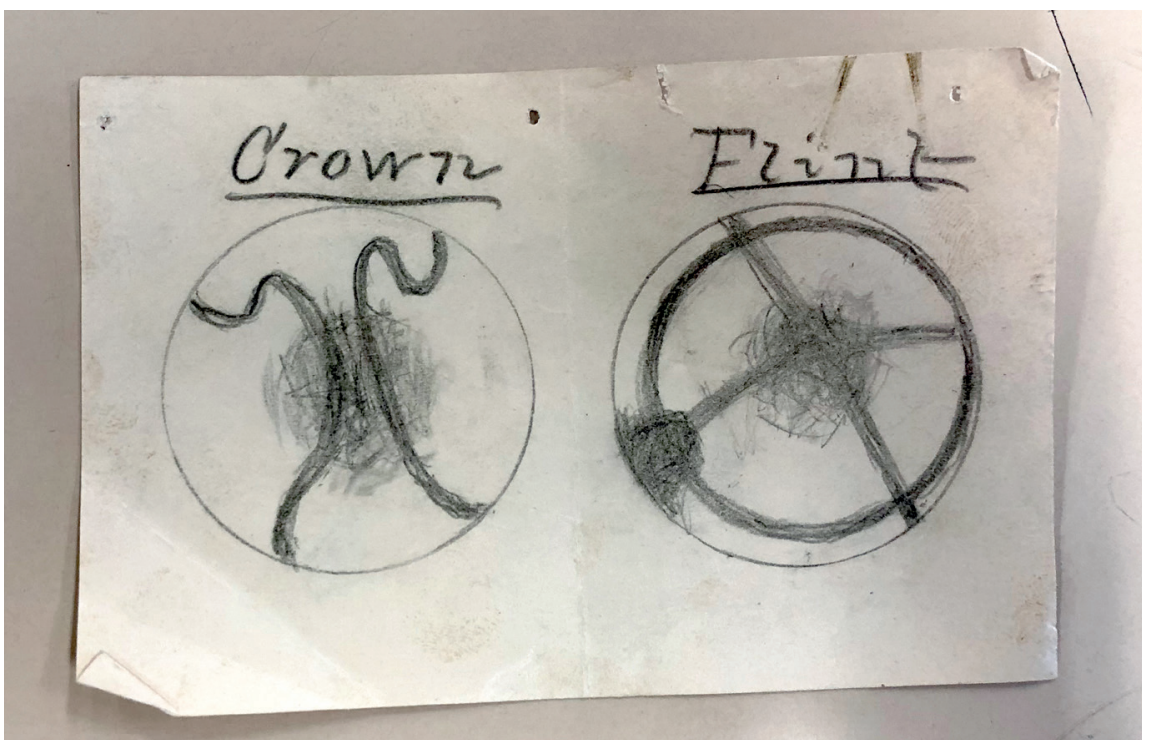

Figura 7. Dibujo que acompaña carta a Felipe Valle, 24 de agosto de 1889, exp. 961, caja 138. Observatorio Astronómico Nacional de Tacubaya, Biblioteca "Guillermo Haro" del Instituto de Astronomía, unAm.

de undécima magnitud que no aparecen con la claridad necesaria; ${ }^{57}$ supuso que, si el instrumento fotográfico estaba en foco y la lente se había reconocido por el Observatorio de Oxford como buena, el problema se encontraba en la falta de coincidencia de los ejes ópticos de las lentes que forman el objetivo y en que la claridad de la apariencia de las estrellas se debía a un revelado insuficiente de las placas.

Felipe Valle, astrónomo del Observatorio, también desarrolló una serie de reflexiones en torno al ajuste que se le debía hacer al telescopio. Describe visualmente las deformaciones de la imagen en forma de "coma o pera" en el ángulo 5.8 de las placas como "una característica de hacer inclinamiento [sic] con exagerada oblicuidad", ${ }^{58}$ explica que las causas que producen los

57 Beltrán y Puga (firmado por), Tacubaya, 24 de diciembre de 1897, AHUNAM FOAN caja 14, exp. 124.

58 Felipe Valle, Reflexiones acerca del ajuste al ecuatorial fotográfico, Tacubaya, diciembre 27, 1897, AHUNAM FOAN caja 39, exp. 399. 
defectos son otras, además de la deformación de la lente, y propone adaptar un método de ajuste: hacer coincidir las lentes para eliminar las deformaciones cromáticas y esféricas y alinear la placa al mismo eje óptico del objetivo. En sus anotaciones describe la forma de pera "más asimétrica que regular" y la acompaña un pequeñísimo dibujo. Explica que esa deformación proviene del reflejo de la misma lente, una especie de fractura óptica por donde la lente refleja la luz y produce figuras triangulares, lo que ahora conocemos con el nombre de destello de lente o flare.

Grubb hizo dos diseños del objetivo fotográfico; el primero era similar al diseño de los hermanos Henry con el vidrio Crown al frente y el segundo era un nuevo diseño con el vidrio Flint al frente. ${ }^{59}$ En 1892 el director del Observatorio de Melbourne identificó que la lente del objetivo fotográfico tenía un defecto de densidad "que hace que sea difícil obtener una buena definición, o la total libertad del paralaje"60 y solicitó a Grubb que le enviara uno corregido. Tras evaluar la posibilidad de arreglar la lente enviándola a Irlanda, Anguiano dispuso en 1899, para reducir costos, mandar a Teodoro Quintana a Massachusetts para que la compañía Alvan \& Clark se encargara de componer el objetivo. En las cartas enviadas a Felipe Valle, Quintana describió las características de las deformaciones de los lentes y adjuntó un pequeño dibujo: "El lente Flint está descentrando y demás grueso de un lado que otro. El Crown está [...] en menor escala”. Los cristales no eran homogéneos, pues según el experto de óptica de la compañía, el sr. Landin, Grubb les había dado lentes de segunda o tercera clase. ${ }^{61}$

59 Jones, "The Scientific Value of the Carte du Ciel", 5.18.

60 Carta al Almirante Mouchez, 25 enero de 1892 (firmada por Ellery), Government Astronomer Melbourne Observatory, en Chinnici, La carte du ciel: Correspondence inédite, 64.

61 Teodoro Quintana a Felipe Valle, 24 agosto de 1899, AHUNAM FOAN caja 138, exp. 961. El astrónomo del Observatorio del Cabo, David Gill, había identificado un defecto mecánico en los tubos del eje de declinación, según lo expresó en una carta al fabricante Howard Grubb, quien acordó "no incluir esa parte objetable" en los siguientes telescopios. Véase lan Glass, Victorian Telescope Makers. The Lives and Letters of Thomas and Howard Grubb 144, 146, citado en Mireles, 27. Mireles también menciona que: "En contraste, para el astrónomo real, William Henry Mahoney Christie, quien declaró durante una visita a los talleres de Grubb que el instrumento mexicano había demostrado ser muy preciso en algunas tomas [...]". De acuerdo con Edgardo Ronald Minniti Morgan, 


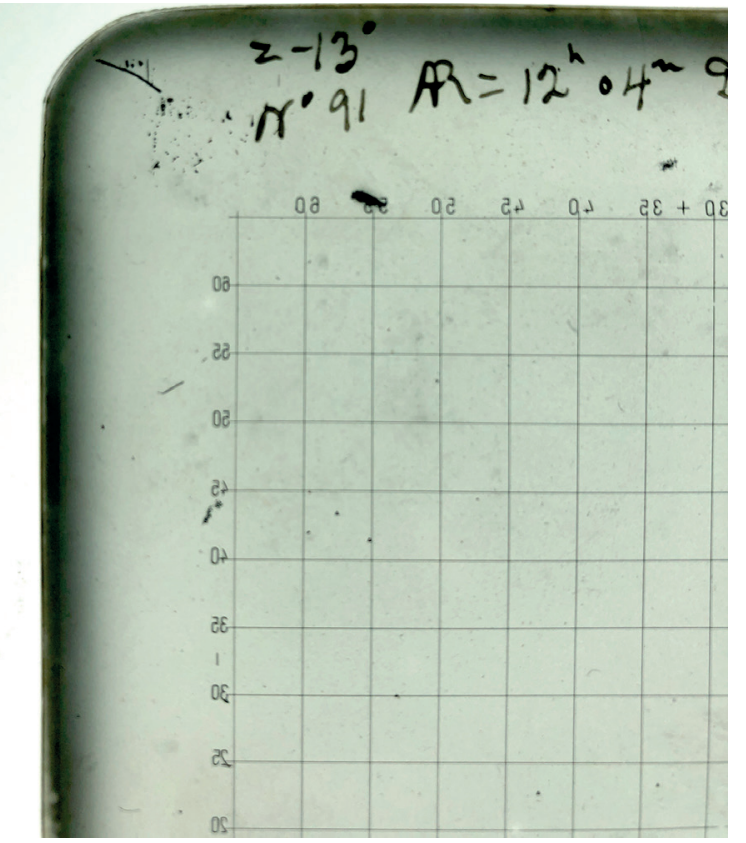

Figura 8. Flare y aberraciones en zonas marginales de la placa. Zona $-13^{\circ} \mathrm{N}^{\circ} 91$.

Observatorio Astronómico Nacional de Tacubaya, Colección Instituto de Astronomía, UNAM.

Deformación y claridad son categorías visuales que permitieron identificar la falta de alineación de los lentes o de revelado de las placas. Las reflexiones en torno a la identificación visual de los errores son también un producto del conocimiento construido a partir de la visualidad. Los astrónomos desarrollaron un juicio dotado de experiencia y recrearon las condiciones de visibilidad necesarias para la examinación de las placas.

En la correspondencia entre Felipe Valle y Loewy, directores de los observatorios de Tacubaya y París, se lee cómo el trabajo realizado por México tomó mucho tiempo más de lo pensado. Valle explica que en el proceso de revisión y reducción:

del Observatorio de Córdoba, los telescopios originalmente estaban destinados a Viena y Niza, pero por razones desconocidas los rechazaron y más tarde los adquirieron astrónomos de Chile y de México. Disponible en http://historiadelaastronomia.files.wordpress. com/2011/07/ristenpart.pdf (consultado el 28 de enero de 2013; referido a pie de página en Mireles, 28). 


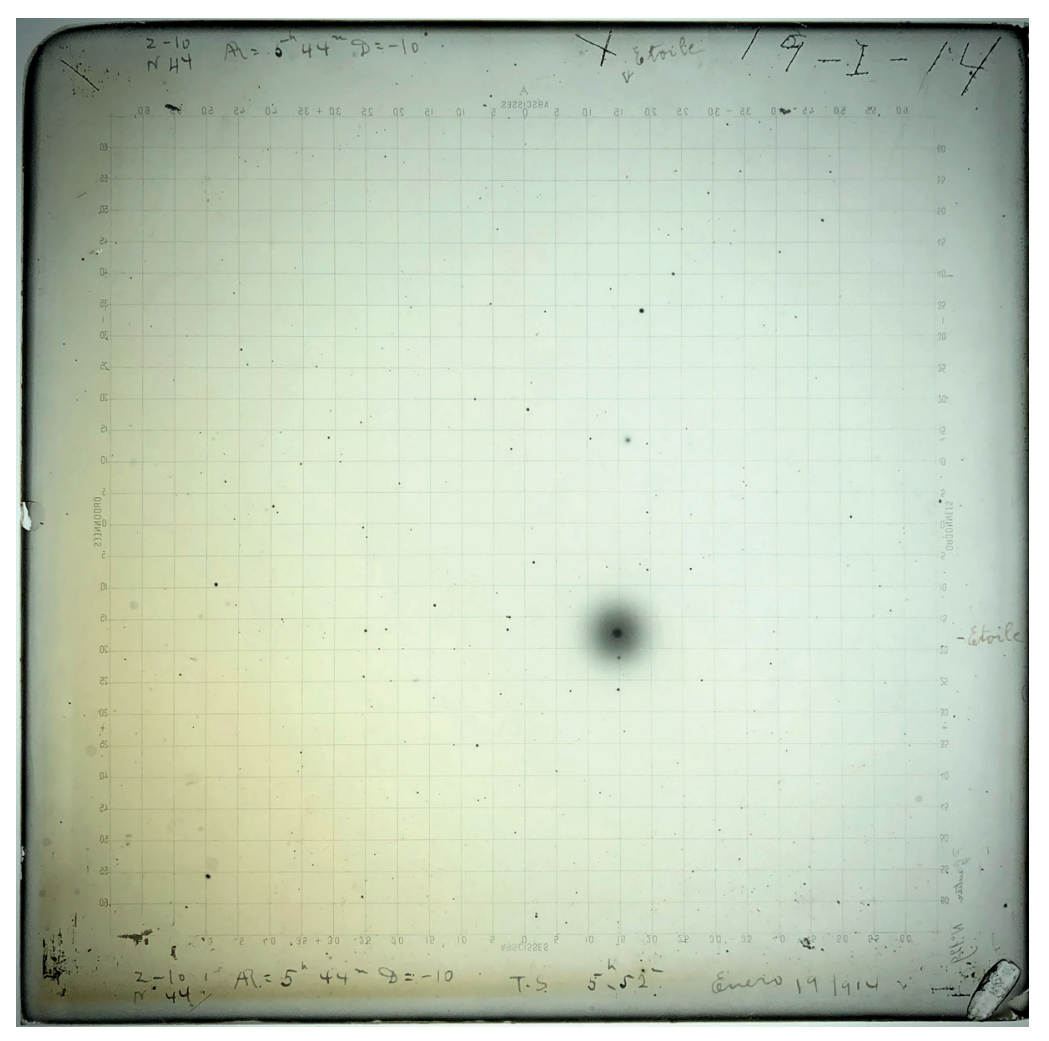

Nierika 20 - Año 10 - julio-diciembre de 2021

Figura 9. Carta del cielo. Zona -10 No 44. T.S. 5h 52m. 19 de enero de 1941.

Observatorio Astronómico Nacional de Tacubaya, Biblioteca "Guillermo Haro" del Instituto de Astronomía, UNAM.

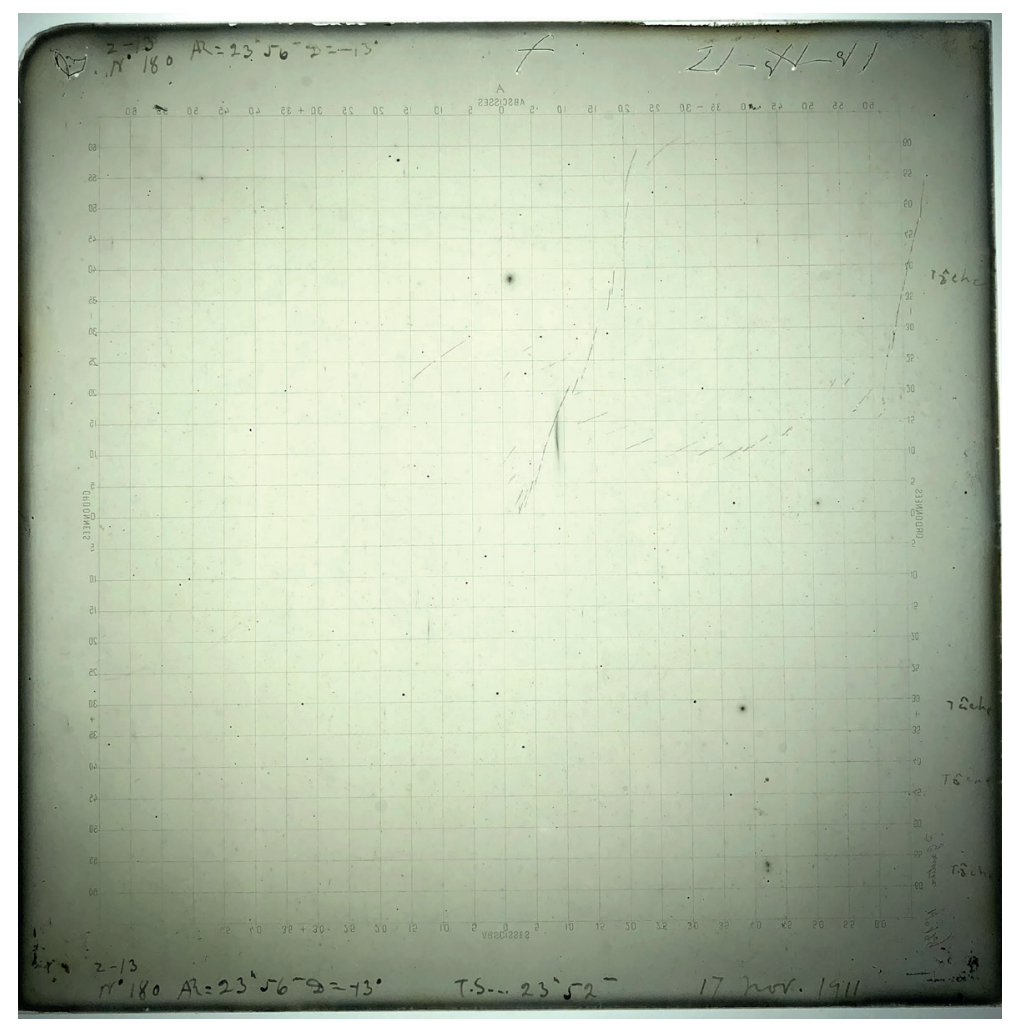

Figura 10. Cuatro signaturas "tâche" en el margen derecho.

Carta del cielo. Zona -130 № 180 T.S. 23h 52m 17 de noviembre de 1911. Observatorio Astronómico Nacional de Tacubaya, Biblioteca "Guillermo Haro" del Instituto de Astronomía, UNAM. 
Hemos rechazado 97 placas por diferentes motivos, y 125 están pidiendo una revisión más cuidadosa, habiéndose tomado con una emulsión no homogénea y con un tiempo de exposición insuficiente, me parece. Medimos 161 clichés del Catálogo, por duplicado, y otros 12 del asteroide Eros: y en 38 de estas placas, redujimos la coordinación en el centro de los clichés como un trabajo de reducción preliminar. ${ }^{62}$

La visualización de los errores en las placas exige un entrenamiento del ojo y la comprensión de la complejidad del proceso de producción. La intervención humana es necesaria para completar el sentido, tanto en la identificación del error como en la visualización de la información. Sólo así podría diferenciarse una estrella formada por tres puntos o asterism, ${ }^{63}$ de cualquier otro tipo de registro no deseado o no identificado. Vale la pena recordar las palabras del astrónomo Joaquín Gallo sobre el trabajo de la Carta del Cielo:

Nada en la naturaleza está en reposo; las estrellas tienen movimientos propios imperceptibles durante una vida a causa de su enorme distancia, pero sensibles al cabo de unos cuantos años si las medidas se han hecho con la precisión necesaria para notar el desalojamiento. ${ }^{64}$

El astrónomo observador, las medidoras y el calculador debían ser conscientes de aquel sutil movimiento a lo largo de los años. La percepción precisa de un ojo educado y un juicio experimentado es lo que develan algunas placas que actualmente resguarda el Instituto de Astronomía de la UNAm. En ellas, es posible identificar el flare con la forma de pera del que hablaba Quintana en zonas no útiles de la placa. Otras más tienen anota-

62 Felipe Valle a M. Loewy, Tacubaya, 18 de marzo de 1909, en Chinnici, La carte du ciel, 382-38 [traducción de la autora]. Antes de 1909 la reducción se hacía con el método trigonométrico de coordenada rectilínea a ecuatorial; a partir de ese año se propuso seguir las indicaciones para calcular la estrella al centro bajo las coordenadas del equinoccio de Greenwich para 1900.

${ }^{63}$ Fresneau A., R. W. Argyle, G. Marino y S. Messina, "Potential of Astrographic Plates for Stellar Flare Detection", 517-524.

64 Gallo, "La Carta del Cielo", 160. 
ciones que diferencian entre una mancha, tâche, de una estrella, etoile. Estas signaturas sobre la placa son propiamente la identificación del error visual, probablemente marcados por el Comité Permanente cuando se enviaron para su revisión.

La producción de la Carta Fotográfica del Cielo generó imágenes con niveles de inteligibilidad en los puntos visibles en el plano. El conocimiento se construye en la interpretación de la visualidad de aquello visible e invisible a los ojos. El ojo debía acostumbrarse y entrenarse para reconocer las figuras y recrear las condiciones de visibilidad necesarias para estudiar las placas; su experiencia y juicio formarán una mirada de experto capaz de construir una visualidad astronómica. La mirada como construcción debe pasar por un proceso de sensibilización, de entendimiento de lo que se ve, de interpretación de lo que se cree ver y de dar sentido. Las formas y figuraciones que aparecen conforman el campo visual y epistémico de la placa: pequeñísimos triángulos equiláteros formados por tres puntos distribuidos en un plano. Para que éstas tuvieran un sentido, sin embargo, se debía mirar más allá de lo visible.

\section{Bibliografía}

Anguiano, Ángel. "Formación de la Carta Celeste por medio de la fotografía". En Anuario del Observatorio Astronómico Nacional de Tacubaya para el año de 1889. Ciudad de México: Secretaría de Fomento, 1888.

- Anuario del Observatorio Astronómico de Tacubaya para el año de 1893. Ciudad de México: Secretaría de Fomento, 1892.

- Anuario del Observatorio Astronómico Nacional de Tacubaya para el año de 1896. Ciudad de México: Secretaría de Fomento, 1895.

- Anuario del Observatorio Astronómico Nacional de Tacubaya para el año de 1897. Ciudad de México: Secretaría de Fomento, 1896.

Bartolucci, Jorge. La modernización de la ciencia en México. El caso de los astrónomos. Ciudad de México: unam, 2000.

Chéroux, Clement. Breve historia del error fotográfico. Ciudad de México: Ediciones Ve, 2018. 
Chinnici, lleana. La carte du ciel: Correspondence inédite conservée dans les archives de l'Observatoire de Paris. París: Observatoire de Paris, 1999.

—. "La Carte du Ciel, genèse, déroulement et issues". En Jérôme Lamy (dir.). La Carte du Ciel. Histoire et actualité d'un project scientifique international. París: L'Observatorie de Paris / EDP Sciences, 2006.

Daston, Lorraine y Peter Galison. Objectivity. Nueva York: Zone Books, 2007.

-. "The Image of Objectivity",Representations, no. 40, Special Issue: Seeing Science (otoño de 1992). University of California Press.

Fresneau, A., R. W. Argyle, G. Marino y S. Messina. "Potential of Astrographic Plates for Stellar Flare Detection", The Astronomical Journal, 121 (2001), 517-524.

Gallo, Joaquín. "La Carta del Cielo", fragmento de La astronomía y la fotografía. Conferencia sustentada en la Asociación de Ingenieros y Arquitectos el 23 de agosto de 1939. Documento procedente del CESU de la UNAM. Transcrito en Luna Córnea, número doble 21/22. Ciudad de México: Centro de la Imagen, 2001.

Gallo, Joaquín. "Solicitud de placas fotográficas especiales de $16 \times 16$ centímetros" (carta de Joaquín Gallo a Kodak Mexicana, 18 enero 1928). Caja 15, exp. 132. FOAN, AHUNAM.

Glass, lan. Victorian Telescope Makers. The Lives and Letters of Thomas and Howard Grubb. Londres: Institute of Physics Publishing, 1997.

Gunthert, André. "Le complexe de Gradiva", Études photograhiques, 2 (1997).

Henry, Prosper y Paul Henry. "On Photographs of a New Nebula in the Pleiades, and of Saturn", Monthly Notices of the Royal Astronomical Society, 46 (1886).

Jones Fras, Derek. "The Scientific Value of the Carte du Ciel", Astronomy \& Geophysics, vol. 41, núm. 5 (octubre de 2000). Disponible en https:// doi.org/10.1046/j.1468-4004.2000.41516.x.

Lamarche-Vadel, Bernard. Lignes de mire. Écrits sur la photographie. París: Marval, 1995.

Lamy, Jérôme (dir.). La Carte du Ciel. Histoire et actualité d'un project scientifique international. París: L'Observatorie de Paris / EDP Sciences, 2006.

_. "The Role of the Conferences and the Bulletin in the Modification of 
the Practices of the Carte du Ciel project at the End of the Nineteenth Century". Journal of Astronomical History and Heritage, 12(2) 119-124 (2009).

__ . "Adjusting Astronomical Practices: 'The Carte du Ciel', the Democratic Rules and the Circulation of Opinions at the End of the $19^{\text {th }}$ century", The Role of Astronomy in Society and Culture Proceeding International Astronomical Union, Symposium núm. 260 (2009).

—. "La Carte du Ciel et la création du 'Bureau des Dames' à I'Observatorie de Toulouse". Nuncius / Istituto e museo di storia della scienza 21(1): 101-120 (2005).

—. "La carte du ciel et l'ajustement des pratiques (Fin xixe - Debut xxe siecle)", en Jérôme Lamy (dir.). La Carte du Ciel. Histoire et actualité d'un project scientifique international. París: L'Observatorie de Paris / EDP Sciences, 2006.

Laskov, Lasko M. y Milcho Tsvetkov. "Data Extraction from Carte du Ciel Triple Images", Serdica Journal of Computing. Bulgarian Academy of Sciences. Institute of Mathematics and Informatics (2013).

Mireles Estrada, Ángel. "La Carta del Cielo: un capítulo internacional de la ciencia mexicana". Tesis de maestría, unAm, 2014.

Moreno Corral, Marco Arturo. "Astrofotografía en el México del siglo XIX", Alquimia, núm. 14, 31 (1994).

—. "Telescopios que han influido en el desarrollo de la astronomía y la astrofísica en México". Quipu, vol. 8, núm. 1 (enero-abril de 1991).

Mouchez, Ernest. La photographie astronomique à l'Observatoire de Paris et la Carte du ciel. París: Gauthier-Villars, 1887.

_. "La Photographie astronomique à l'Observatoire de Paris et la carte du ciel Paris, 1887". En R. Radau (ed.). II. Bulletin du Comité international permanent pour l'exécution photographique de la carte du ciel, 1888-1889. París: Bureau de la Revue des Deux Mondes, 1889.

Snyder, Joel. "Visualization and visibility". En Caroline A. Jones, Peter Galison (eds.). Picturing Science, Producing Art. Nueva York/Londres: Routledge, 1998.

Téllez Fabiani, Enrique. "Observatorio Astronómico Nacional: trabajos fotográficos y geográficos bajo la dirección de Ángel Anguiano (1877-1899)". Tesis de maestría, UAM, 2003. 
Urban, S. E., et al. "The AC 2000: The Astrographic Catalogue on the System Defined by the Hipparcos Catalogue", The Astronomical Journal 115, 1212-1223.

Wayman, P. A. "The Grubb Astrographic Telescopes, 1887-1896". En S. Debarbat, et al. (eds.). Mapping the Sky: Past Heritage and Future Directions: Proceedings of the 133rd Symposium of the International Astronomical Union, held in Paris, France, 1-5 June 1987. Suzanne Debarbat (ed.). International Astronomical Union. Symposium núm. 133. Dordrecht: Kluwer Academic Publishers: Disponible en http://adsabs. harvard.edu/full/1988IAUS.133.139W (consultado el 5 de julio de 2020). Wilder, Kelly. Photography and Science. Londres: Reaktion Books, 2009.

\section{Archivos consultados}

Archivo Histórico de la Universidad Nacional Autónoma de México, Fondo Observatorio Astronómico Nacional. Proyectos astronómicos: Carta del Cielo.

Colección Fotográfica del Instituto de Astronomía, UNAM.

\section{Mariana Rubio de los Santos}

Licenciada en Historia del Arte por la Universidad Iberoamericana, donde colaboró como becaria en la línea de investigación Arte y Educación del Departamento de Arte, y maestra con mención honorífica en Historia del Arte por la UNAM en el campo de conocimiento de Arte Moderno con enfoque en los inicios de la fotografía en México. Actualmente realiza un doctorado en Historia del Arte en la misma institución con una investigación que cuestiona lo fotográfico y la visualidad en las imágenes científicas de la Luna de principios del siglo xx. 